\title{
Level of Seeking Marital Counseling Among Married in Siaya County (Kenya)
}

\author{
Rosemary Judith Akoth Odhiambo, Catherine Mumiukha, George Makori \\ Department of Psychology, Counselling and Educational Foundations, Egerton University, Nakuru, Kenya \\ Email address: \\ jrodhiambo1970@gmail.com (R. J. A. Odhiambo)

\section{To cite this article:} \\ Rosemary Judith Akoth Odhiambo, Catherine Mumiukha, George Makori. Level of Seeking Marital Counseling Among Married in Siaya \\ County (Kenya). American Journal of Applied Psychology. Vol. 10, No. 5, 2021, pp. 120-127. doi: 10.11648/j.ajap.20211005.13
}

Received: August 23, 2021; Accepted: September 3, 2021; Published: October 30, 2021

\begin{abstract}
Counseling in marriage is aimed at enhancing social cohesion, values, behaviour and beliefs. However, counseling in many African societies remains superficial. The purpose of this study was to establish the level of seeking marital counseling among fishers in Siaya County of Kenya. The purpose of this study was to establish the level of seeking marital counseling among fishers in Siaya County of Kenya. The study used Mixed Methods Research, with a Convergent Mixed Research Design. The population comprised 10370 registered married fishers in the main landing sites of Siaya County from where a sample size of 99 married fisher were selected. Data was collected using interview schedule for married fishers. Most fishers sought marital counseling for serious problems which also varied according to age, length of marriage, type of marriage and parenting status. The study recommends couple's marital counseling be put in place to help the fishers experience marital stability. The study also recommends marital counseling should be enhanced and done at integrated level to procure solutions to marital problems.
\end{abstract}

Keywords: Marital Counseling, Marital Happiness, Siaya, Kenya, Fishers Communities

\section{Introduction}

The union of two people in marriage is construed to be a long term physical, emotional, spiritual and social investment to each other [1]. Couples strive to live together in marriage and enjoy the closest possible loving and fulfilling relationship [2]. The "ideal" of married love for most people include romance, friendship and devotion [3]. Every marriage has an expectation of longevity [4] which should be met with honesty, commitment and sacrifice in the marital partnership [5]. Achieving longevity in marriage however has proved difficult because marriage is a delicate relationship of persons who relatively speaking, are strangers to each other $[6,7]$. As a result, marital relationships get strained at some time and produce self-reinforcing, maladaptive patterns which constitute negative interaction cycles [8]. Some of these pressures may at times, boil and overwhelm a family and sometimes changes within the marriage may leave other members confused, angry or hurt [9]. Changes in situations like financial state, physical health, and the influence of other family members can have a profound influence on the conduct, responses and actions of the individuals in a relationship.

Marital counseling comes in handy in giving the married partners an opportunity to explore their situation, discover and find solution or answers to a problem [10]. If well utilized counseling may creates hope, shape people's relationship and enhances marriage stability for those who turn to it as an alternative [11]. It may address issues of cohesiveness, disconnection, unmet needs, and misunderstanding and help the family members work proactively to disrupt unhealthy marital behavioral patterns $[12,13]$. As counseling may be considered a means of intervention, it remains a powerful and an influential force in human society. It is generally agreeable, that marital counseling is important for both the participants and the marriage itself. The purpose is to prepare the couple for marriage and to create a healthy and growing relationship. Marital counseling considers patterns that frequently mirror habitual interactions at home and therapy interventions usually focus on what goes on between individuals rather than within one or more individuals $[14,15]$. By reviewing a past incident and suggesting alternative ways, couples may have responded to one another during it, or instead proceed 
directly to address the sources of conflict at a more abstract level, as by pointing out patterns of interaction that the couple might have not noticed [16].

In Kenya, Siaya County is dominated by a population which belongs to the Luo community and dominantly speak the same language and have similar practices. The main livelihoods of the Luo people are fishing, farming and pastoral herding. The Luos in Siaya County and other counties in Kenya are known to strictly adhere to sociocultural norms [17] key of which is the ethnicity [18] as well as religious beliefs. [19-21]. Studies on the level of marital stability in Siaya County among the Luo communities was generally described as satisfactory but in some instances, the levels were found to be low needing marital counseling [22]. The decline of marital stability has continued to be experienced and fishers showing a sign of family distress cases and low marital stability have been reported with a dire need of marital counseling [23] ed. With the rising plea of family despair, there is need to help fisher couples. There is, however, lack of studies on marital counseling in the region. This study established level of seeking marital counseling among fishers in Siaya County, Kenya.

\section{Methodology}

\subsection{Research Design}

The study used a mixed methods research which involves collecting, analyzing, and interpreting quantitative and qualitative data in a single study or in a series of studies that investigate the same underlying phenomenon [24]. The current study utilized concurrent transformative design where both the qualitative and quantitative data were collected at the same time. In this research design qualitative and quantitative data was collected and analyzed simultaneously allowing for perspectives from each to be explored. The conduct of the study was informed by a theoretical perspective and data that was integrated during the interpretation phase.

\subsection{Location of the Study}

The study was conducted in Siaya County which is one of the six counties in the Nyanza region (Appendix F). The county is about $400 \mathrm{~km}$ from Nairobi, the Kenyan Capital City. The altitude of the County rises from $1,140 \mathrm{~m}$ on the shores of Lake Victoria to $1,400 \mathrm{~m}$ above sea level on the North. Siaya County is dominated by Luo people speaking Luo dialect. The main livelihoods of the Luo people in Siaya County are fishing, farming and pastoral herding however fishing is more practiced. The county is divided into six subcounties namely; Siaya, Gem, Bondo, Rarieda, Ugenya and Ugunja. Siaya County has 67 beaches, however the researcher focused on the main landing sites which include Kadenge, Ndayi, Kamariga and Usenge. Siaya County was chosen because of the reported cases of low marital stability in earlier literature [23].

\subsection{Target Population of the Study}

The study population comprised of 10370 registered married fishers in the main landing sites of Siaya County, 75 beach leaders and 23 religious' leaders (Siaya County Statistics, 2018). The total population was derived from the six sub counties. The total number of people in each sub county are [25]: Siaya (224,343), Bondo (197,883), Gem $(179,792)$, Rarieda $(152,570)$, Ugenya $(134,354)$ and Ugunja $(104,241)$. The target population comprised 10,370 residents at the landing sites. Table 1 summarizes the distribution of the population size at the landing sites.

Table 1. Distribution of Population Size at Landing Sites.

\begin{tabular}{|c|c|c|c|c|c|c|c|c|c|}
\hline \multirow{2}{*}{$\begin{array}{l}\text { Landing } \\
\text { Sites }\end{array}$} & \multicolumn{3}{|c|}{ Fishers } & \multicolumn{3}{|c|}{ Beach Leaders } & \multicolumn{3}{|c|}{ Religious Leaders } \\
\hline & Male & Female & Total & Male & Female & Total & Male & Female & Total \\
\hline Kadenge & 952 & 1354 & 2306 & 8 & 3 & 11 & 3 & 2 & 5 \\
\hline Kamariga & 1084 & 1531 & 2615 & 13 & 4 & 17 & 4 & 1 & 5 \\
\hline Usenge & 1192 & 1743 & 2935 & 27 & 6 & 33 & 5 & 1 & 6 \\
\hline Total & 4207 & 6163 & 10370 & 60 & 15 & 75 & 17 & 6 & 23 \\
\hline
\end{tabular}

Source: Siaya County Statistics (2018).

\subsection{Sample Size and Sampling Procedures}

From a target population of each unit, the sample size was determined using Yamane formula [26]: thus

$$
n=\frac{N}{1+N e^{2}} \text {. }
$$

Where $\mathrm{n}=$ required responses

$\mathrm{N}=$ Population

$\mathrm{e}^{2}=$ error limit ( 0.1 for samples between 100 to 1000 )

Married fishers were determined as: $\mathrm{n}$ for respondents $=\frac{10370}{1+10370 * 0.1^{2}}=99$

The researcher strived to ensure that among the two leaders at each site, one was a male and the other was female. Purposive sampling was done among beach and religious leaders who had interacted with fishers or have been at the landing site the longest. The sample size was arrived at as shown in table 2. The married fishers, beach leaders and religious leaders were stratified into male and female. The sample size of male and female fishers was determined as a proportion of the total population. Simple random sampling 
was then utilised to identify the female and male fishers.

beach leaders and 8 religious' leaders (Table 2).

Therefore, the desired sample size was 99 married fishers, 8

Table 2. Distribution of Sample Size.

\begin{tabular}{llllllllll}
\hline \multirow{2}{*}{$\begin{array}{l}\text { Landing } \\
\text { sites }\end{array}$} & Fishers & \multicolumn{9}{c}{ Beach Leaders } & \multicolumn{3}{c}{ Religious Leaders } \\
\cline { 2 - 10 } & Male & Female & Total & Male & Female & Total & Male & Female & Total \\
\hline Kadenge & 9 & 12 & 21 & 1 & 1 & 2 & 1 & 1 & 2 \\
Ndayi & 9 & 15 & 24 & 1 & 1 & 2 & 1 & 1 & 2 \\
Kamariga & 10 & 17 & 27 & 1 & 1 & 2 & 1 & 1 & 2 \\
Usenge & 11 & 17 & 28 & 1 & 1 & 2 & 1 & 1 & 2 \\
Total & 40 & 59 & 99 & 4 & 4 & 8 & 4 & 4 \\
\hline
\end{tabular}

Source: Siaya County Statistics (2018).

Accordingly, Kadenge had a total of 31, Ndayi had a total of 37, Kamariga had a total of 41 while Usenge had a total of 52 respondents being fishers, religious leaders and beach leaders as presented in table 2 .

\subsection{Instrumentation}

The instrument for data collection was interview schedule for the fishers, interview guide for beach leaders and interview guide for religious leaders. Items in the interview schedule were designed and used to collect data directly from the married fishers while the interview guide was designed to collect data from the beach leaders and religious leaders. The items were in both closed and open-ended structure and administered to all sampled fishers. The instruments were designed to ensure the in-depth exploration of personal views, feelings and opinions the extent to which the selected socio-cultural practices affect marital stability and counseling. Interview guide was designed and used in order to get detailed information from the beach leaders and religious leaders of the fishers. The researcher recorded the sessions which were later transcribed and coded according to the emerging themes for analysis.

The scoring of the instrument was done to establish the levels of marital stability, seeking of marital counseling, religious beliefs and ethnic values. In determining the marital stability, 28 items based on Likert scale 1 to 5 were used where the lowest score was 28 and maximum score of 140 . To determine seeking marital counseling, a total of 15 items with Likert scores were used. For the religious values, the number of items were 15 while ethnic values also having 15 items based on Likert scores of 1 to 5 . The scoring of these variables is presented in Table 3.

Table 3. Scoring Metrics for the Instruments in the Instruments.

\begin{tabular}{ll}
\hline Scores & Level of seeking marital counseling \\
\hline$<37.5$ & Basic issues \\
$37.5-52.5$ & More serious Issues \\
$>52.5$ & Desperation and Crisis \\
\hline
\end{tabular}

\subsection{Validity and Reliability of the Instruments}

The researcher developed the interview schedule and guide in line with the research objectives. The salience of the instruments was sought by providing the interview schedule and guides to three experts in the field of Counselling Psychology at the Department of Counselling Psychology of Egerton University. This was to purposely ascertain the item's face and content validities. Their comments and suggestions were used to improve the items in the instruments.

The reliability of instruments was established through a pilot study in Luanda Kotieno Beach. Twenty married fishers participated in the pilot study. Cronbach's coefficient alpha was used to determine the internal consistency of the items in the interview schedule. The study considered the instrument reliable and acceptable if the computation yielded a reliability coefficient of 0.7 and above, which is considered acceptable in most social sciences research [27]. The reliability coefficient estimated was 0.87 and it was considered adequate.

\subsection{Data Collection Procedure}

Once the research proposal was approved, the researcher obtained the introductory letter from the Graduate School, Egerton University. The researcher then applied for a research permit from the National Commission for Science, Technology and Innovation (NACOSTI). Thereafter the researcher visited the study area and through the beach leaders, planned with individual respondents on the appropriate date and time for data collection. The researcher assistants were trained for 2 weeks on how to conduct interviews with the respondents for the data collection. The entire data collection exercise was one month. The researcher used two research assistants who communicated in the local dialect.

\subsection{Data Analysis}

Collected data was coded and entered into Statistical Package for Social Sciences (SPSS) version (23.0) computer package [28] before analysis. Data on characteristics of the fishers, marital stability, seeking marital counseling, religious belief and ethnic values were analyzed through frequencies and percentages. Significant differences between seeking marital counseling relative to age of marriage, length of marriage, type of marriage and parental status were analyzed using chi-square.

\subsection{Ethical Issues}

This study adhered to the ethical standards required in 
research vis-a-vis: anonymity, confidentiality and informed consent. Anonymity was ensured by not collecting and identifying information of individual subjects (e.g., name, address, Email address, etc). Confidentiality was ensured by not divulging the identity of the respondents or their organizations. Informed consent to participate in the study was obtained from the study participants including authorization from the beach management leaders. These measures enhanced the willingness and objectivity of the respondents.

\section{Results and Discussion}

\subsection{Response Rate}

The researcher sampled 99 married fishers, 43 beach leaders and 19 religious' leaders. The respondents were provided the questionnaires and the response rates to the questionnaires are presented in Table 4.

Table 4. Response Rate to the Interview Schedule and Interview Guide.

\begin{tabular}{llll}
\hline Respondents & Sample Size & Number of Respondents & Response Rate (\%) \\
\hline Married Fishers & 99 & 95 & 96 \\
Beach Leaders & 43 & 42 & 93.3 \\
Religious Leaders & 19 & 16 & 84.2 \\
Total & 163 & 153 & 93.9 \\
\hline
\end{tabular}

Response rate for the married fishers was $96.0 \%$ while that of the beach leaders was $93.3 \%$ and religious leaders $84.2 \%$. These response rates were considered very good when compared to the recommended response rates to verify consistency of measurements required for analysis of over 60\% [29].

\subsection{Characteristics of the Married Fishers}

Table 5 summarizes fishers' characteristics by age, parenting status, type of family and type of marriage.

Table 5. Characteristics of Married Fishers.

\begin{tabular}{llll}
\hline \multirow{2}{*}{ Variable } & Range & Married fishers $(\mathbf{n}=\mathbf{9 5})$ & Percent \\
\cline { 3 - 4 } & & Frequency & 12.6 \\
Age & $18-25$ years & 12 & 17.9 \\
& 26-35 years & 17 & 32.6 \\
\multirow{3}{*}{ Parenting status } & 36-55 years & 31 & 36.8 \\
& >55 years & 35 & 75.8 \\
Type of marriage & Parenting & 72 & 24.2 \\
& Non-parenting & 23 & 100 \\
& Total & 95 & 33.7 \\
& Monogamous & 32 & 66.3 \\
\hline
\end{tabular}

Among the married fishers, $36 \%$ of the respondents were aged over 55 years, while $32.6 \%$ were aged between 36 to 55 years, and those between 18 to 25 years were $12.6 \%$. Age distribution was skewed towards elderly who are mainly above the age of 35 years. In most parts of Africa, marriages take place when a man is around 30 to 35 years and the woman around 26 to 30 years $[30,31]$. Most men in newly wed relationships are often in major towns in search of livelihood and therefore chances of encountering young couples in rural areas is often low. Several years ago, marriage among women in most of sub-Saharan Africa could be described as early and near-universal [32-34]. However, it is apparent that over the last three decades there is a trend toward delays in the onset of marriage, with early marriage becoming less frequent among the populace [35]. The study established that $76 \%$ of the married fishers were parenting. The study established that polygamy still dominated the marriage type even among the religious leaders. Approximately $85 \%$ of societies in the anthropological record permit men to marry multiple wives [36] thus taking several wives is always positively associated with status, wealth or nobility [37]. Polygamy is one of the many practices still rampant in many African societies which is an ethnic customs for many African based societies [38-40], thus it is not surprising to establish that in the current study, polygamy was more dominant.

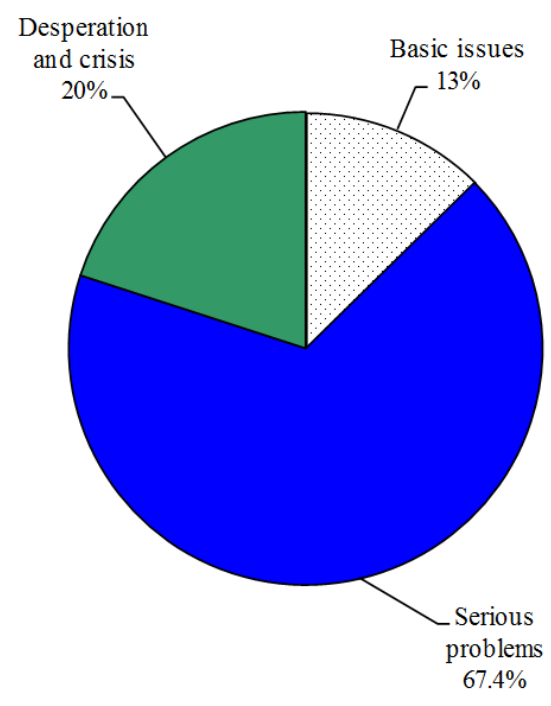

Figure 1. Level of Seeking Marital Counseling among Fishers. 


\subsection{Level of Seeking Marital Counseling Among Fishers}

The level of seeking marital counseling based on the response by the fishers, is presented in Figure 1.

According to Figure 1, 67.4\% of the respondents were seeking marital counseling for serious problems which suggests that there were a number of serious challenges in marriage that affect the marriage and that counseling must be sought. Those seeking counseling for desperation and crisis in their marriage had $20 \%$ while those who sought counseling for basic issues had $12.6 \%$. Marital problems can sometimes be very serious that may attempt to break up the marriage. Couples at this stage may also not be able to comprehend due to heighten emotions and getting the right solution may fail. Counseling therefore is vital to help the couple unlock the dark areas and be able to get solution to the problem. There are also other problems that marital people may seek counseling for including: Jealousy, lack of communication; betrayal or affair, lack of trust; different sexual need; and different goal and value. These listed problems usually cause instability in marriages; thus, counseling is recommended as soon as discontent arises in a relationship, and that it is good to seek for a solution to the problem by visiting a therapy. Marital counseling aims at helping individuals to learn skills useful for resolving marital conflicts [41]. Successful marital counseling often resolves most of the problems that causes unstable marital relationship, the success of marital counseling session depend on each partner motivation and dedication to the process and couples can expect to become better listeners and communicators and to find new ways to support one another [42]. Convenient and conducive environment is needed for ensuring the required privacy and comfort, the counselor's office is normally used to achieve these [43]. The counselor is expected to be able to decide on the structure to be applied during the counseling session. There are recommended methods available, among which a counselor is expected to choose from and apply during the marital counseling.

\subsection{Constructs of Seeking Marital Counseling}

The study further sought to establish the level of seeking marital counseling by age, length of marriage and type of marriage. Percentage of the fishers with different levels of seeking marital counseling against age, length of marriage and type of marriage is shown in Table 6. Difference in level of seeking marital counseling by age, length of marriage and type of marriage is shown in Table 6 .

Table 6. Level of marital stability by age, length of marriage and type of marriage.

\begin{tabular}{lllll}
\hline \multirow{2}{*}{ Age (years) } & \multicolumn{2}{l}{ Level of seeking marital counseling by percentage } & & Total \\
\cline { 2 - 5 } & Basic issues & Serious problems & Desperation and crisis & 12.6 \\
\hline $18-25$ & 4.4 & 8.4 & 0 & 17.9 \\
$26-35$ & 1.1 & 11.6 & 5.3 & 32.6 \\
$36-55$ & 3.2 & 21.1 & 8.4 & 36.8 \\
$>55$ & 4 & 26.3 & 6.3 & 100 \\
Total & 12.6 & 67.4 & 20 & 32.6 \\
Length of marriage & & & 0 & 8.4 \\
$<1$ year & 7.4 & 25.3 & 4.2 & 31.6 \\
1-5 years & 1.1 & 3.2 & 6.3 & 27.4 \\
6-10 years & 3.2 & 18.9 & 9.5 & 100 \\
$>$ 10 years & 1.1 & 20 & 20 & \\
Total & 12.6 & 67.4 & & 33.7 \\
Type of marriage & & 17.9 & 7.4 & 66.3 \\
Monogamous & 8.4 & 49.5 & 12.6 & 100 \\
Polygamous & 4.2 & 67.4 & 20 & \\
Total & 12.6 & & \\
\hline
\end{tabular}

Fishers who those who sought marital counseling for basic issues were aged 18-25 years or elderly aged over 55 years. Majority of those with more serious issues seeking counseling were aged over 55 years while those who sought counseling for desperation and crisis were aged above 35 years. The differences were significant $(P<0.05)$. The results suggest that people sought marital counseling for basic issues at the start of the marriage and for more serious issues as marriage advances. It has been documented that few couples engage in therapy prior during marriage until the conditions are already difficult [44]. This suggests that barriers prevent couples from seeking or receiving help. One of the key barriers that have been established to prevent the couples from seeking help is the age. With data collected from couples living in low-income communities, it was identified that the most common barriers endorsed by couples who did not receive treatment when needed, is the young age of the couples [45]. Research on young couples suggest that many distressed couples either do not seek help at all or wait until their problems are very severe before doing so [46]. Most couples find it difficult to make decision on whether to go for counseling or remain silent with their marital challenges thus they are not able to receive help [47]. Concerning length of marriage, most fishers sought marital counseling for basic issues at $7.4 \%$ had less than a year in marriage. This confirms the fact that marriage at an early stage may be smooth and without challenges since couples are still at the stage of knowing each other and intimacy may also still be very active. The study established that the married fishers seeking marital counseling for serious problems had been married for 6-10 years. Meanwhile those who sought marital counseling for desperation and crisis 
were married for more than 10 years. The early years of marriage can bring some of the greatest joys - and biggest pitfalls. Busy routines with work, hectic traveling schedules, pressure of achieving targets and goals, etc., might not really leave any time for any kind of communication leading to stress and fatigue giving way to irritated attitudes, which can spark unpleasant conversations that further lead to arguments. This kind of life may spread for a period until when the couples go through experiences that shape them with age and their period of marriage. As concerns, parenting, couples who were parenting were seeking marital counseling had serious issues $(47.4 \%)$. There were no significant differences in the level of seeking marital counseling among the different age groups $(P>0.05)$, thus the age of seeking of marital counseling was not different based on age of the couples. The results indicate that seeking marital counseling was not different for parenting and nonparenting respondents where most of them sought counseling for serious issues.

Table 7. Relationship between marital stability by age, length of marriage and type of marriage.

\begin{tabular}{llll}
\hline & Pearson Chi-Square & df & p-value \\
\hline Age of the fishers & 18.899 & 6 & 0.0017 \\
Length of marriage & 17.497 & 6 & 0.0081 \\
Type of marriage & 3.237 & 6 & 0.4122 \\
\hline
\end{tabular}

During the interview concerning seeking marital counseling, the issues towards marital counseling, the beach leaders and religious leaders indicated that many of the married fishers who had marital challenges were not willing to attend counseling of any form. This agrees with other studies in the region who indicated that many African communities rarely seek marital counseling due to their cultural orientations [48]. One of the religious leader also indicated that the local community members were more negative towards counseling which agrees with other studies done in Nigeria [49]. Furthermore, interviews indicated that there are no proper counseling services within the area as well as willingness by the government, county government as well as well wishers to supporter counselors in the region. The result of the interview supports the quantitative responses from fishers about low level of seeking marital counseling. The beach leaders indicated that married fishers lack any form of counseling which makes them develop negative attitudes towards counseling.

\section{Conclusions and Recommendations}

Most fishers sought counseling for serious problems. This suggests that most of the married fishers sought some form of help when they faced serious challenges such as emotional issues, unfaithfulness, communication challenges, intimacy and lack of commitment. The study also established that the level of seeking marital counseling differed with age where majority of the married fishers aged 18-25 years sought marital counseling for basic issues, while majority of the couples aged over 55 years sought marital counseling for serious problems.
In terms of seeking marital counseling by length of marriage, the findings indicate that majority of the married fishers with less than 1 year in marriage sought marital counseling for basic issues and serious problems, while majority of the couples who were married for over 10 years sought marital counseling for desperation and crisis. Most of those fishers who sought marital counseling for basic issues were in monogamous marriages as compared to those in polygamous marriage. The findings also indicated that most of the couples who were parenting sought marital counseling for basic issues. Generally, more parenting couples sought marital counseling than nonparenting couples.

The fishers can be encouraged to seek marital counseling even when they are not encountering serious problems. Moreover, workshops and seminars should be arranged by different stakeholders to enlighten the fishers on the importance of marriage and the need to practice good marital attributes that will enhance marital stability.

\section{Author's Contributions}

RJAO, made substantial contributions to beginning and design, collection of data, analysis and interpretation of data and in drafting the manuscripts and correcting the comment given by the advisors. CM, involved in revising the research paper and the manuscript critically for important intellectual context and approval of the final version to be published and participated in its design and coordination. GM involved in revising the research paper and the manuscript critically for important intellectual context and approval of the final version to be published and participated in its design and coordination.

\section{References}

[1] Hughes, P. (2018). Marriage, family life and faith in 2016. Pointers: Bulletin of the Christian Research Association. 28 (1), 1 .

[2] Whyte, M. K., (2018). Dating, mating, and marriage. Routledge.

[3] Halwani, R., (2018). Philosophy of love, sex, and marriage: an introduction. Routledge.

[4] Fatima, M., (2018). Marital Stability among Women and its Effect on Social Development of Children. Aligarh Muslim University.

[5] Uğur, E. (2016). Marital Attitudes as a Mediator on the Relationship between Respect toward Partner and Subjective Happiness. Journal of Family, Counseling and Education. 1 (1), 25-30.

[6] Bernstein, M., B. Harvey, and N. A. Naples. (Year). Marriage, the Final Frontier? Same-Sex Marriage and the Future of the Lesbian and Gay Movement. in Sociological Forum. 2018. Wiley Online Library.

[7] Jarnkvist, K. (2019). Childbearing and Marriage: Investigating the Importance of Context for Meaning-Making of First-Time Marriage. Marriage \& Family Review. 55 (1), 38-58. 
[8] Soleimani, A. A., et al. (2015). The effectiveness of emotionally focused couples therapy on sexual satisfaction and marital adjustment of infertile couples with marital conflicts. International journal of fertility \& sterility. 9 (3), 393.

[9] Mirecki, R. M., et al. (2013). What factors influence marital satisfaction? Differences between first and second marriages. Journal of Divorce \& Remarriage. 54 (1), 78-93.

[10] Nystul, M. S., (2015). Introduction to counseling: An art and science perspective. Sage Publications.

[11] Zarei, E., et al. (2018). The Comparison of the effectiveness of group counseling based on Gottmanś theory and Glasserś choice theory on increasing marital satisfaction and decreasing marital conflicts in married women. Hormozgan Medical Journal. 22 (2), 77-86.

[12] Baker, A. M. (2019). Marital Stability and Spiritual Growth: A Phenomenological Study On Christian Premarital Counseling.

[13] Isfahani, N. N., et al. (2018). Effectiveness of counseling based on mindfulness and acceptance on the marital conflict of intercultural married women in Iran. Contemporary Family Therapy. 40 (2), 204-209.

[14] Sagesse, W., (2018). Relationships between Premarital Counseling, Religiosity, and Marital Satisfaction. Grand Canyon University.

[15] Shakarami, M., et al. (2015). Effectiveness of brief solutionfocused group couple therapy on improving marital quality in women. Razi Journal of Medical Sciences. 22 (131), 1-13.

[16] Cickerman, N. W. (2017). The family approach to marital disorders. Experimentation and Innovation in Psychotherapy. 176.

[17] Ketter, C. K. and M. C. Arfsten. (2015). Cultural value dimensions and ethnicity within Kenya. International Business Research. 8 (12), 69.

[18] Cohen, D. W., (1989). Siaya: the historical anthropology of an African landscape. East African Publishers.

[19] Atieno-Odhiambo, E. (2000). Luo Perspectives on Knowledge and Development: Samuel G. Ayany and Paul Mbuya. African Philosophy as Cultural Inquiry. 244.

[20] Ojwang, H. J. (Year). Toward a Social Philosophy of the African Leviratic Custom: How Luo. in African philosophy at the threshold of the new millinium [sic]: papers of the 7th Annual Conference of the International Society for African Philosophy and Studies (ISAPS). 2005. Addis Ababa University Print. Press.

[21] Harries, J. O., (2007). Pragmatic theory applied to Christian mission in Africa: with special reference to Luo responses to 'bad'in Gem, Kenya. University of Birmingham.

[22] Onyango, P. and H. P. Obuya. (2020). Martial stability across four counties of Nyanza Region: What are the possible factors response? International Journal of Academic Research and Studies. 4 (2), 34-41.

[23] Potash, B. (1978). Some aspects of marital stability in a rural Luo community. Africa. 48 (4), 380-397.

[24] Bentahar, O. and R. Cameron. (2015). Design and Implementation of a Mixed Method Research Study in Project Management. Electronic Journal of Business Research Methods. 13 (1).
[25] Kenya National Bureau of Statistics. (2018). Kenya economic survey.

[26] Yamane, T. (1973). Statistics: An introductory analysis.

[27] Taber, K. S. (2018). The use of Cronbach's alpha when developing and reporting research instruments in science education. Research in Science Education. 48 (6), 1273-1296.

[28] SPSS, I. (2011). IBM SPSS statistics for Windows, version 20.0. New York: IBM Corp. 440.

[29] Greco, L. M., et al. (2018). Meta-analysis of coefficient alpha: A reliability generalization study. Journal of Management Studies. 55 (4), 583-618.

[30] Maswikwa, B., et al. (2015). Minimum marriage age laws and the prevalence of child marriage and adolescent birth: evidence from sub-Saharan Africa. International Perspectives on Sexual and Reproductive Health. 41 (2), 58-68.

[31] Kaufman, B. M. L. R. J. and A. Nandi. (2015). United States Menu. International Perspectives on Sexual and Reproductive Health. 41 (2), 58-68.

[32] Okpewho, I., (2018). Understanding African marriage: Towards a convergence of literature and sociology, in Transformations of African marriage. Routledge. 331-345.

[33] Hunter, M. (2016). Introduction: new insights on marriage and Africa. Africa Today. 62 (3), vii-xv.

[34] Phillips, A., (2018). Survey of African marriage and family life. Routledge.

[35] Shapiro, D. and T. Gebreselassie. (2014). Marriage in subSaharan Africa: Trends, determinants, and consequences. Population Research and Policy Review. 33 (2), 229-255.

[36] Wamwara, J. J. (2019). A Case for Legalizing Polygamy in Western Societies: Lessons from the Global South. Law \& Ineq. 37, 75 .

[37] Lawson, D. W. and M. A. Gibson. (2018). Polygynous marriage and child health in sub-Saharan Africa: What is the evidence for harm? Demographic Research. 39, 177-208.

[38] André, P. and Y. Dupraz, (2019). Education and Polygamy: Evidence from Cameroon. University of Warwick, Department of Economics.

[39] Amone, C. (2019). Polygamy as a Dominant Pattern of Sexual Pairing Among the Acholi of Uganda. Sexuality \& Culture. 1-16.

[40] Fenske, J. (2015). African polygamy: Past and present. Journal of Development Economics. 117, 58-73.

[41] Thomas, M., (2019). Counseling the Executive Couple: A Modified Approach to Marital Therapy for Professionals Experiencing Relationship Distress. Widener University.

[42] Baruth, L. G. and M. L. Manning, (2016). Multicultural counseling and psychotherapy: A lifespan approach. Routledge.

[43] Carlson, R. G., et al. (2017). Characteristics of couples who attend family services counselor visits in relationship education. Marriage \& Family Review. 53 (1), 48-64.

[44] Suomi, A., et al. (2019). Couple and family therapies for posttraumatic stress disorder (PTSD). Cochrane Database of Systematic Reviews. (12). 
[45] Williamson, H. C., B. R. Karney, and T. N. Bradbury. (2019). Barriers and facilitators of relationship help-seeking among lowincome couples. Journal of Family Psychology. 33 (2), 234.

[46] Pitta, P. J. and C. C. Datchi, (2019). Integrative couple and family therapies: Treatment models for complex clinical issues. American Psychological Association.

[47] Mahmoodi, G. (2016). The effect of marriage counseling on the knowledge of the married couples. Int J Med Res Health Sci. 5 (7S), 354-35.
[48] Lema, V. M. (2014). Unconsummated marriage in subSaharan Africa. African journal of reproductive health. 18 (3), 159-169.

[49] Oladeji, D. (2013). Psychosocial factors influencing marital adjustment among couples in Ile-Ife, Osun State, Nigeria. International Journal of Home Economics. 6 (2), 250. 